\title{
Replication of a dynamic coaching program for college students with acquired brain injury
}

\author{
Jerry K. Hoepner, Mandi Salo, Haley Weich \\ Communication Sciences and Disorders Department, University of Wisconsin - Eau Claire, WI, USA
}

Purpose: To replicate a dynamic, individualized coaching intervention for two students with acquired brain injury who were transitioning back to college after their injury.

Methods: Two individuals with acquired brain injury participated in a two-semester coaching intervention. A case study comparison was used to compare quantitative and qualitative outcomes.

Results: Students improved on cognitive standardized test scores, as well as grades. Use of prompted and unprompted metacognitive statements improved for both students. One student increased reported use of strategies, while the second student was inconsistent with strategy use. One student completed the majority of credits attempted, moving toward fulltime status by completion of coaching intervention. The second student dropped about one third of her enrolled credits each semester and withdrew from the university in the semester following the coaching intervention.

Conclusions: It is feasible to replicate a dynamic, individualized coaching intervention to foster strategy use and self-regulatory behaviors in students with acquired brain injuries. Given the heterogeneity of acquired brain injuries, outcomes varied substantially between students. Keywords: Coaching intervention, College transition, Acquired brain injury, Self-regulation

\section{INTRODUCTION}

For the 2.2 million Americans who sustain a traumatic brain injury (TBI) each year [1], the process of returning to pre-injury roles and productivity can be a daunting, though feasible task. An estimated 3.2-5.3 million people live with TBI related disabilities [2-4]. Because teenagers and young adults ages 15-19 are some of the most common victims of TBI [5], the challenge overcoming brain damage while being enrolled in post-secondary education is of particular importance. Among these young persons with TBI, there is great variation in cognitive abilities as well as awareness of the impairment [610]. Taking such variations into account, survivors of TBI tend to display some level of learning difficulty, especially in acquiring and recalling new information, as well as the use of necessary learning strategies to do so [6-13]. In a survey given to students with TBI concerning their college experiences, the most commonly reported issues were of academic difficulty as a result of memory deficits. Kennedy and colleagues distributed the survey in two, separate studies $[14,15]$. The first study included 35 individuals with TBI [14]. Forty-one adults with TBI and 36 controls were included in the second study [15]. An overwhelming $97 \%$ of survey participants self-reported the need to review ma-

(C) 2019 The Korean Association of SpeechLanguage Pathologists

This is an Open Access article distributed under the terms of the Creative Commons Attribution NonCommercial License (http://creativecommons.org/ licenses/by-nc/4.0/) which permits unrestricted noncommercial use, distribution, and reproduction in any medium, provided the original work is properly cited. 
terial more than prior to their injury [14,15]. Other complaints included increased nervousness for exams, time-management difficulties, attention deficits, forgetfulness, and being overwhelmed by studying $[14,15]$. In fact, $81 \%$ reported reducing their course load or even dropping out of college as a result $[14,15]$. In addition to the aforementioned cognitive issues, various physical, psychosocial, and spiritual factors add to the challenges faced by individuals with TBI [16]. Dawson et al. [16] examined return to productivity (i.e., return to work or school) four years post onset of TBI $(n=46)$. Along with time to recover memory, physical status (pain) and psychological status (depression, coping) were central to productivity outcomes. It is no surprise that college retention and graduation rates are significantly lower for students with TBI than students without [17].

There is a distinct relationship between the frontal lobe of the brain and executive functioning [18]. Executive functions include higher-level thinking and processing skills, such as attention, working memory, inhibition, and multitasking [18]. The monitoring and control one has over their own memory system, termed metamemory, is of specific importance [19]. Metamemory, also defined as a general awareness of one's own memory $[13,20]$, is associated with the frontal lobe as well $[13,21]$. Metamemory is known to provide an overall awareness during learning that allows one to gauge their future recall abilities and direct study activities [13,20]. One type of metamemory judgment is the judgment-of-learning (JOL), a process by which one assesses their likelihood to recall a certain piece of learned information $[20,22]$. The average student will allot more study time for information that is more likely to be recalled and less study time for what they feel is likely to be recalled [19]. Without such self-regulated learning, it is nearly impossible to effectively implement even such basic learning strategies [9]. In the past, JOLs have been generally known to be quite inaccurate at predicting recall [22]. However, Nelson and Dunlosky [22] found that JOLs made after a short time lapse just after studying an item can create nearly perfect recall prediction. They found that, as opposed to immediate JOLs, delayed JOLs produced greater recall prediction accuracy for $100 \%$ of test subjects [22]. There are many theories as to why this "delayed JOL effect" exists [22,23]. One such theory suggests that when subjects assess their memory immediately after acquisition, they may be simultaneously monitoring their short-term memory and long-term memory [22].

Numerous studies have linked impaired recollection with TBI [13,15,24-31]. TBI survivors remember less information than controls, even when provided with more study time $[13,26]$. However, an individual's self-regulation within learning is equally important [9]. This includes the analysis of their abilities, coupled with good choices in effective and flexible strategies for achieving their own set goals [8,9]. Executive dysfunction is a result of frontal lobe damage commonly associated with TBI [12,13,21,32-34]. Furthermore, many individuals with TBI are also unaware of the extent and implications of their injury [12]. For example, one study specifically describes an individual with TBI who considers herself as having average attention skills while her mother describes her as having a severe attention deficit [35]. Inconsistencies in self-assessments were prominent in this case series $(n=4)$, where partners of persons with brain injury consistently identified more problems than the individuals with TBI [35]. The presence of impairments to self-perception four years post onset of severe TBI in participants whose recovery was good enough to allow for pursuit of a college education speaks to the pervasiveness of this impairment. Conversely, during learning, a non-braininjured individual will constantly be monitoring, or assessing their current state of learning in comparison to an internal goal, and using self-control to minimize the gap between those two states [12]. Executive dysfunction, particularly metamemory impairments, make such processes difficult for individuals with TBI [12,13,21].

Interestingly, the delayed JOL effect is preserved in individuals with TBI $[12,13]$. Studies have shown that TBI survivors are just as accurate at predicting recall as control groups when making delayed JOLs [12,13]. Kennedy et al. [13] asked 18 adults with acquired brain injury and 16 controls to make immediate and delayed recall predictions. Delayed recall predictions were more accurate than immediate recall predictions for both groups, however; those with acquired brain injury were less accurate than controls. This suggests that delayed recall predictions are a better basis than immediate recall predictions for making decisions. The previous investigation by Kennedy and Yorkston [12] used a similar paradigm with 18 adults with TBI and 18 controls. Clinical implications are that decision making is best informed by delayed judgments of learning. This is not to say that metamemory impairments are easy for students with TBI to overcome. When making immediate JOLs, when making JOLs throughout a lengthy learning task, or when faced with answer uncertainty, individuals with TBI still tend to overestimate their abilities $[13,19,26]$.

Clearly, impairments in metamemory and JOL challenge learning outcomes in a variety of learning tasks. There are fed- 
eral laws requiring colleges and universities that receive federal assistance to provide services for students with disabilities $[15,36]$. However, students must still be assertive in seeking out such assistance. Whether it is because they are not aware of the long-term effects of their injuries or because they do not want to be labeled as "impaired," many students with TBI choose not take advantage of the resources offered to them [15]. In this study, less than half of the respondents had never used their school's disability services. Additionally, only $20 \%$ have never even heard of disability services. This is just a small element relating to why many campuses are ill equipped to provide assistance to students with TBI. When a student with TBI enters or returns to college, they face the substantive challenge of re-learning how to learn. Since brain injuries manifest themselves very differently in each student, individualized support in coping with and learning how to be successful, in spite of brain injury, is vital $[8,9]$.

Kennedy and colleagues [9] investigated a self-regulatory, individualized coaching intervention for college students with TBI. The investigation included two 20 -year-old males who were re-entering college after a TBI (14 and 10 months postinjury respectively). The intent was to examine the feasibility of providing individualized coaching and provide evidence of individual changes following participation in the intervention. Both students demonstrated gains in self-regulatory strategies, although there was substantial discrepancy in the outcomes for student one versus student two. It is important to recognize that poorer outcomes reported in the second student do not necessarily indicate shortcomings of the coaching program. This may simply reflect the heterogeneity of impairments and preserved functions following TBI. Self-awareness levels appear to be central to those participant differences in this case. Further, student one participated in more coaching sessions, had more hours of coaching interactions, and identified more specific strategies than student two. Nevertheless, student two continued to seek support and adjusted his goals, suggesting that self-awareness was beginning to change over time. Factors such as self-determination and motivation appear to have affected student outcomes. As such, further examination of such factors is warranted. Both students demonstrated substantial gains on standardized assessments of cognition, including gains in language, visual special skills, and memory. Given the extensive time required to deliver an individualized coaching intervention, numbers of student outcomes remain low. As such, replication of such case series allows for validation and ongoing development of such pro- gramming.

The present investigation sought to replicate the Kennedy and colleagues' [9] dynamic coaching intervention for college students with TBI. In addition to paralleling design methods and quantitative outcome measures, the present investigation will provide further qualitative information about outcomes. Part of the intent of examining qualitative outcomes is to address factors related to motivation and self-determination.

\section{METHODS}

\section{Participants}

Two college students with acquired brain injuries were recruited through a flyer, which was distributed to local hospitals, rehabilitation centers, and outpatient care providers. Student 1 (S1) was an 18-year-old female with a TBI who was three months post-injury. She was referred by a local practitioner who was nearing completion of outpatient services. She presented initially with a GCS of 5 and a coma duration of 13 days, indicating a severe injury. Student 2 (S2) was a 40-yearold female who was 14 months post-onset of an embolic cerebrovascular accident of the left middle cerebral artery. The authors decided to include S2 based upon her general presentation, which matched the criteria for students with impairments in executive functions and self-regulation, returning to college after onset. She initially experienced mild aphasia and anomia, which had since resolved but problems with higher-level processing persisted. Unfortunately, we were unable to access the results of specific cognitive-communication assessments, as only summaries were provided in her medical record. Note that although aphasia was present initially, no evidence of aphasia was present at the outset of her enrollment in this program. The results of pre- and post-testing are included in the results section. She was referred by a professor in the Communication Sciences and Disorders (CSD) program at our university who was familiar with our work. That student had initiated coursework in the CSD major, given her positive experiences with the clinicians who worked with her during rehabilitation, but she struggled in those courses. Neither student had mental health or neurological diagnoses, aphasia, motor speech disorders, or histories of learning disabilities prior to their brain injuries.

The investigation was approved by the University of Wisconsin - Eau Claire institutional review board (IRB protocol number 4552012), and participants provided written consent of their agreement to participate in the study. Intervention be- 
gan during S1's first semester upon returning to school following injury and continued through the second semester of enrollment post-injury. Intervention began during S2's third semester post-injury and continued through her fourth semester. Minimal follow up and tracking was conducted in subsequent semesters.

\section{Pre- and post-intervention measures}

Measures obtained to gauge student history, progress, and current state included: medical history records; standardized test scores; personal living, work, and family situation; and academic transcripts and records including GPA, credits attempted, and previous college experiences. These details are discussed in results in order to pair them with each case description.

Pre- and post-test measures used in the Kennedy and Krause [9] investigation were replicated, including the Repeatable Battery for Assessment of Neuropsychological Status [37] (RBANS), the American National Adult Reading Test [38] (AMNART), the Functional Assessment of Verbal Reasoning and Executive Strategies [39] (FAVRES). Trained graduate students administered and scored pre- and post-testing measures. Note that the Adult Functional Communication Measures (FCM) of Spoken Language Expression and Comprehension were added to characterize expressive and receptive language [40]. A speech-language pathologist with 20 years of clinical experience rated Spoken Language Expression and Comprehension by viewing video recorded interactions in the initial session, pre-intervention and the final session, post-intervention.

The students also completed the College Survey for Students with Brain Injury [15] (CSS-BI). Student responses to the CSS-BI were used in interviews where students were asked to expand on their answers by providing examples and details. Interviews were performed by the second author prior to intervention.

\section{Coaching intervention}

The students participated in weekly coaching sessions about their successes and struggles in returning to school and achieving their academic goals following injury. A substantial amount of time during coaching sessions was spent assessing each student's perceived performance versus actual performance. Each of the students self-assessed her studying effectiveness, test performance, and assignment performance. Each meeting was spent evaluating the effectiveness of specific study strategies, suggesting alternatives, and directly coaching study methods.

The dynamic coaching approach incorporated motivational interviewing techniques [41] to foster collaborative exploration of potential learning strategies. One of the challenges of a coaching approach, which is intended to facilitate change in studying approaches, is to avoid simply serving as a tutor. The motivational interviewing approach addresses this, as it emphasizes evoking the client's own potential solutions and planning action steps, rather than simply suggesting solutions. Coaches employed the techniques of open-ended questions, affirming, reflecting, and summarizing (OARS) to foster person-centered decision making. Along with evoking and planning techniques, designed to elicit the participant's own potential solutions and actionable steps, the approach was paired with the strategy-based coaching approach.

Prior to starting intervention during the first semester, the student participants were tested, surveyed, and interviewed. The same testing was performed again at the end of the second semester of student participation. Trained graduate students conducted and scored each test.

\section{Procedures and analyses}

Interactions were recorded using the PDS Intelligent Stream Recording system at the University of Wisconsin - Eau Claire Center for Communication Disorders Clinic. A Sony digital audio recorder (ICD-SX733) was used to ensure adequate audio fidelity for transcription. Interviews and intervention coaching sessions were transcribed by two research assistants. Research assistants were randomly assigned to transcribe interviews/sessions and were blinded to the dates of those interviews/sessions.

Transcriptions were reviewed by all authors to become immersed in the data. Next, transcripts were analyzed, using a simple categorical content analysis sort [42], to identify coaching prompts and client metacognitive statements. Coaching prompts were operationally defined as questions or cues to consider a strategy to address a learning challenge. Metacognitive statements were operationally defined as statements conveying reflection on one's own performance and awareness of quality of that performance. Metacognitive statements were identified and counted by authors two and three independently. Next, all three authors met to negotiate consensus on statements. Because the content was objective and fairly discrete, $100 \%$ consensus was reached within the second round of coding. Metacognitive statements were documented 
as a complete thought and patient statements were not removed from their immediate context when analyzing statement word count.

The ratio between statements that were on-task (related to strategy use for homework and preparation for exams) versus those off-task (including attempts to elicit tutoring and reteaching from the coach, along with simple chit chat) was calculated to serve as a measure of efficiency.

\section{RESULTS}

\section{Case study 1 \\ Participant}

S1 was an 18-year-old female who graduated high school just prior to sustaining a TBI in a motor vehicle accident. Her hospital stay was 65 days, including 13 days in a coma. Outpatient physical therapy, speech-language pathology, and occupational therapy were nearing completion at the initiation of our intervention. Prior to sustaining her injury, S1 had completed 25 college credits through her high school post-secondary enrollment option program (PSEO) at a local community college. Upon graduation, she transferred those credits with a 3.55 grade-point average (GPA) to the University of Wisconsin - Eau Claire, where she intended to pursue pre-medicine. Only 85 days post-injury, S1 began undergraduate work at the University of Wisconsin - Eau Claire, at which time she changed her major to accounting and decided to take all online courses for a time. She was referred to our dynamic coaching program for additional academic support and transition assistance from an outpatient speech-language pathologist (SLP). That SLP reported concerns over euphoric laughter that did not match the context and that she was multitasking and listening to heavy metal music while she studies. She reported that listening to heavy metal music helped her to study. Participation in the study began when S1 was 106 days post-injury and coaching interactions began four weeks into her first semester of returning to college post-injury. See Figure 1 for the timeline of her injury and return to school.

\section{Pre-intervention measures}

Pre-intervention measures replicated assessments used by Kennedy and Krause [9], including the RBANS [37], AMNART [38], FAVRES [39], and the CSS-BI [15]. Subscale scores from testing completed one week prior to intervention can be seen in Table 1.

\section{CSS-BI}

S1 identified six areas of difficulty out of 16 general categories listed on the CSS-BI. She reported experiencing and receiving therapy for decision-making problems, physical impairment of the arms/hands, memory problems, and organization problems. She also reported attention problems and fatigue as well as a write-in response of struggling with double-vision. Out of 13 student experience statements, S1 agreed with three, acknowledging that she forgets what has been said in class, has to review material more than she used to, and has trouble paying attention in class or while studying. No time management or relating to others effects were openly expressed.

To examine potential effects of language impairments on study outcomes, the Adult Functional Communication Measures (FCM) of Spoken Language Expression and Comprehension were used to characterize expressive and receptive language [40]. Pre-intervention scores for Spoken Language Expression and Comprehension were both 6. A Spoken Language Expression score of 6 indicated that the person was able to communicate successfully in most contexts, although there were some limitations present in vocational, avocational, and social activities. A Comprehension score of 6 indicated the ability to understand with rare, minimal cueing for complex sentences.

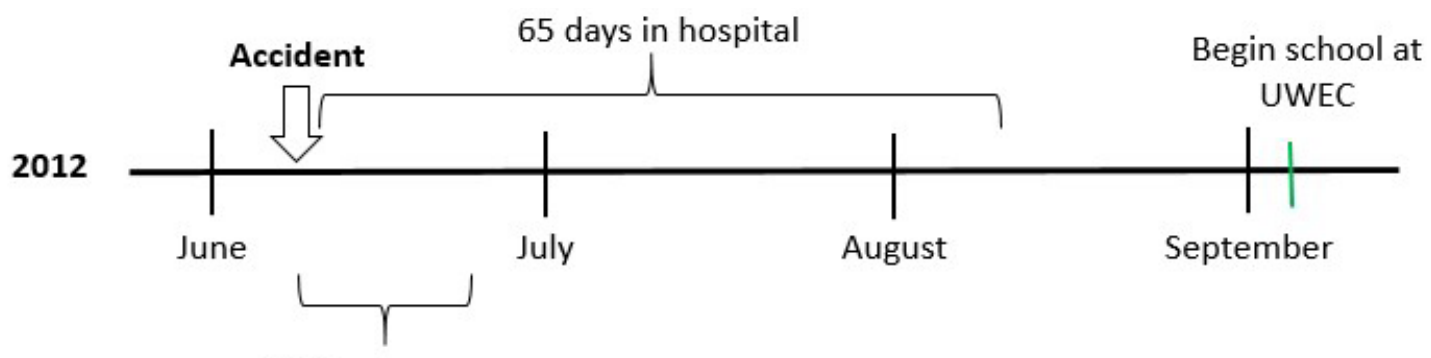

13 days in coma

Figure 1. Timeline for $S 1$, initial college education, onset of $\mathrm{TB}$, and return to university. 
Table 1. Comparison of student RBANS pre- and post-intervention

\begin{tabular}{|c|c|c|c|c|}
\hline & \multicolumn{2}{|c|}{ S1 } & \multicolumn{2}{|c|}{ S2 } \\
\hline & Pre-intervention & Post-intervention & Pre-intervention & Post-intervention \\
\hline \multicolumn{5}{|l|}{ RBANS } \\
\hline Immediate memory (percentile) & $87^{b}$ (19th) & $112^{f}$ (75th) & $87^{b}$ (18th) & 90 (25th) \\
\hline List learning & 29 & $35^{e}$ & 27 & 26 \\
\hline Story memory & 18 & 21 & $13^{b}$ & 15 \\
\hline Delayed memory (percentile) & 94 (34th) & 97 (43rd) & $83^{b}$ (13th) & 94 (34th) \\
\hline List recall & $6^{b}$ & 5 & $3^{c}$ & $0^{d}$ \\
\hline List recognition & 20 & 20 & 20 & 19 \\
\hline Story recall & 9 & 11 & $7^{b}$ & $7^{\mathrm{b}, \mathrm{g}}$ \\
\hline Figure recall & 15 & $18^{e}$ & 11 & 14 \\
\hline Language (percentile) & $82^{\mathrm{c}}$ (12th) & $104^{e}$ (59th) & $87^{b}$ (18th) & 90 (25th) \\
\hline Semantic fluency & $15^{c}$ & $24^{f}$ & 21 & 17 \\
\hline Naming & 9 & 10 & $8^{b}$ & $10^{e}$ \\
\hline Attention (percentile) & $85^{b}$ (16th) & $103^{e}$ (58th) & $79^{\mathrm{c}}$ (8th) & $115^{f}$ (84th) \\
\hline Digit span & 12 & 13 & 10 & $13^{\mathrm{e}}$ \\
\hline Coding & $41^{c}$ & $58^{e}$ & $33^{d}$ & $52^{f}$ \\
\hline Visuospatial (percentile) & 100 (50th) & 112 (75th) & 116 (84th) & 126 (96th) \\
\hline Figure copy & $16^{d}$ & $20^{f}$ & 19 & 20 \\
\hline Line orientation & 20 & 19 & 20 & 20 \\
\hline RBANS Total Score (percentile) & $85^{b}$ (16th) & $107^{e}$ (68th) & $86^{b}(17$ th) & $103^{\mathrm{e}}$ (58th) \\
\hline AMNART & 117.84 & 118.72 & 135.08 & 136 \\
\hline FAVRES SS Total accurate & $40^{d}(<1 s t)$ & $91^{f}(31 s t)$ & 101 (49th) & 111 (100th) \\
\hline FAVRES SS Total rationale & $60^{d}(3 r d)$ & $89^{e}$ (21st) & $82^{b}$ (13th) & $97^{e}$ (32nd) \\
\hline FAVRES SS Total time & 121 (94th) & 118 (91st) & 107 (66th) & 113 (80th) \\
\hline
\end{tabular}

FAVRES, Functional Assessment of Verbal Reasoning and Executive Strategies; AMNART, American National Adult Reading Test; RBANS, Repeatable Battery for Assessment of Neuropsychological Status.

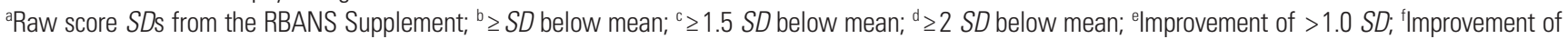
$>2.0 S D$; ' Decline of $>1.0 S D$.

\section{Coaching intervention}

During the first semester of intervention, S1 was enrolled in 7 credits online: a 5-credit Introduction to College Writing course and a 2-credit Wellness \& Fitness course. S1 participated in a total of 11 weekly coaching sessions with an average duration of 33 minutes ( $S D=13.68$, range 19-63 minutes).

To address studying and learning, coaches assisted S1 with her writing course. At the request of S1, limited session time was devoted to her wellness course. No accommodations were provided by the Center for Students with Disabilities that directly related to these courses. Writing strategies included outlining papers, reading writing out loud for sentence flow and clarity, and analyzing the writing of others. Coaching session time was spent breaking down the task of a large final paper into smaller parts. Coaches and S1 worked together to edit the paper in phases focusing on different graded elements: content, organization, citations, sentence structure and flow, and grammar and mechanics. S1 had a tendency to overestimate the approximate grade that her paper would receive. For example, in one session she stated “There's no way I'm not getting an A+ on this paper...it's honestly so good that I think I would get an A+ if I turned it in right now. I know this essay is just like a masterpiece it belongs in an art gallery." Unfortunately, at that point, it was not as outstanding as she reported. Breaking the paper down into smaller parts was beneficial in reframing the overwhelming paper into smaller parts to be improved.

S1 did not report any difficulty with time management on the CSS-BI. However, in the first semester of intervention, this domain was addressed in coaching sessions with discussion 
on S1's use of time management tools. At the beginning of the semester, S1 used at least four time-management tools: a large wall-mounted calendar, an exhaustive hand-written todo list, a planner, and an electronic calendar. Coaches encouraged S1 to condense her agenda into three tools at most. S1 later reported a transition to primary reliance on her electronic calendar with secondary support of a planner. She reported that this method was more efficient and less confusing and overwhelming. Eventually, S1 rejected this strategy, reverting back to her original way of thinking, stating that it had worked prior to her injury and that she liked the way she had always done it.

To address relating to others in the first semester, coaching session time was spent discussing the role S1's mother should play in her return to college. The intervention program encourages a strong support system, which S1 had. However, coaches found that $S 1$ would benefit from decreasing the level of dependency on her mother over time. At the beginning of the semester, Sl's mother played the primary role in correspondence between the student and coaches. The strategy was implemented by asking S1 to directly correspond with coaches by email and slowly transition to being the sole recipient of all communication on her school email address. Over time, S1 gained independence, eventually managing her own email, to-do lists, and homework; post-intervention, she decided to move out of her mother's home and take on the responsibility of leasing an apartment with other roommates.

In the second semester of intervention, S1 was initially enrolled in 12 credits in the classroom. However, she immediately dropped two classes and changed to six online credits: a 3-credit Principles of Accounting II course and a 3-credit Information Systems in Business course. In-person classrooms still presented too many distractions that made it hard for her to focus. $S 1$ participated in 11 weekly coaching sessions with an average duration of 39 minutes $(S D=8.88$, range 29-52 minutes).

As a reflection of the status of her attention and self-regulation at the time, it is helpful share a story she shared in one of her coaching sessions, early in the second semester. She opened the session by sharing how excited she was because she got her driver's license back and it was her first day of driving to campus on her own. Unfortunately, on her way to campus, something was wrong with her car, so she pulled over to check on it. When she stepped out of the car, she inadvertently locked the doors, locking herself out. Not upset by the minor setback, she called her mom to come with another key. Her mom was sleeping at the time, as she worked the night shift. Arriving to the coaching session a few minutes late, she shared the story with a smile on her face, not a bit upset by the incident, just happy to be driving again. While this story speaks to deficits that still remained at the time, it also speaks to the enthusiasm and motivation that would propel her forward in recovery.

At the request of S1, studying and learning intervention focused primarily on her Accounting course, with little time spent on her Information Systems course. Accommodations allowed by the Center for Students with Disabilities included $50 \%$ additional time for exams. The emphasis of coaching sessions was on studying strategies for accounting, particularly as they relate to online courses: making flashcards, doing practice problems, teaching others, and taking effective notes from the textbook.

Time management was addressed in the second semester by coaches helping S1 to plan her next semester, particularly because she had failed to correctly assess her ability to handle a 12-credit in-person course load the previous semester. S1 and coaches worked together to plan course schedules and a timeline for graduation. Intervention was necessary as S1 displayed difficulty understanding her limits. Weekly commitments were mapped to help S1 make decisions regarding how many classes to take and how many hours to take on at work.

Relating to others was not directly addressed in the second semester, but the same topics addressed in the first semester continued to be emphasized.

\section{Post-intervention measures}

Post-testing was completed four weeks after the last coaching session of semester two. Her RBANS total score improved from the 16th to the 68th ( $>1 S D)$, immediate memory improved from the 19th to the 75th ( $>2 S D$ ), delayed memory from the 34 th to the 43rd, language from the 12th to the 59th ( $>1 S D$ ), attention from the 16th to 58th ( $>1 S D$ ), and visuospatial processing from the 50th to 70th percentile. AMNART scores improved from 117.84 to 118.72 . Total scores on the FAVRES improved from $<1$ percentile to 31st $(>2 S D$ ) for accuracy, from the 3rd to 21st percentile ( $>1 S D$ ) for rationale, and remained steady (94th to 91st percentile) for time. For a comparison of post-testing outcomes for both students, see Table 1.

The Adult Functional Communication Measures (FCM) of Spoken Language Expression and Comprehension were used to characterize expressive and receptive language [40]. Postintervention scores for Spoken Language Expression and 
Table 2. S1 grades prior to TBI, during intervention, and post-intervention

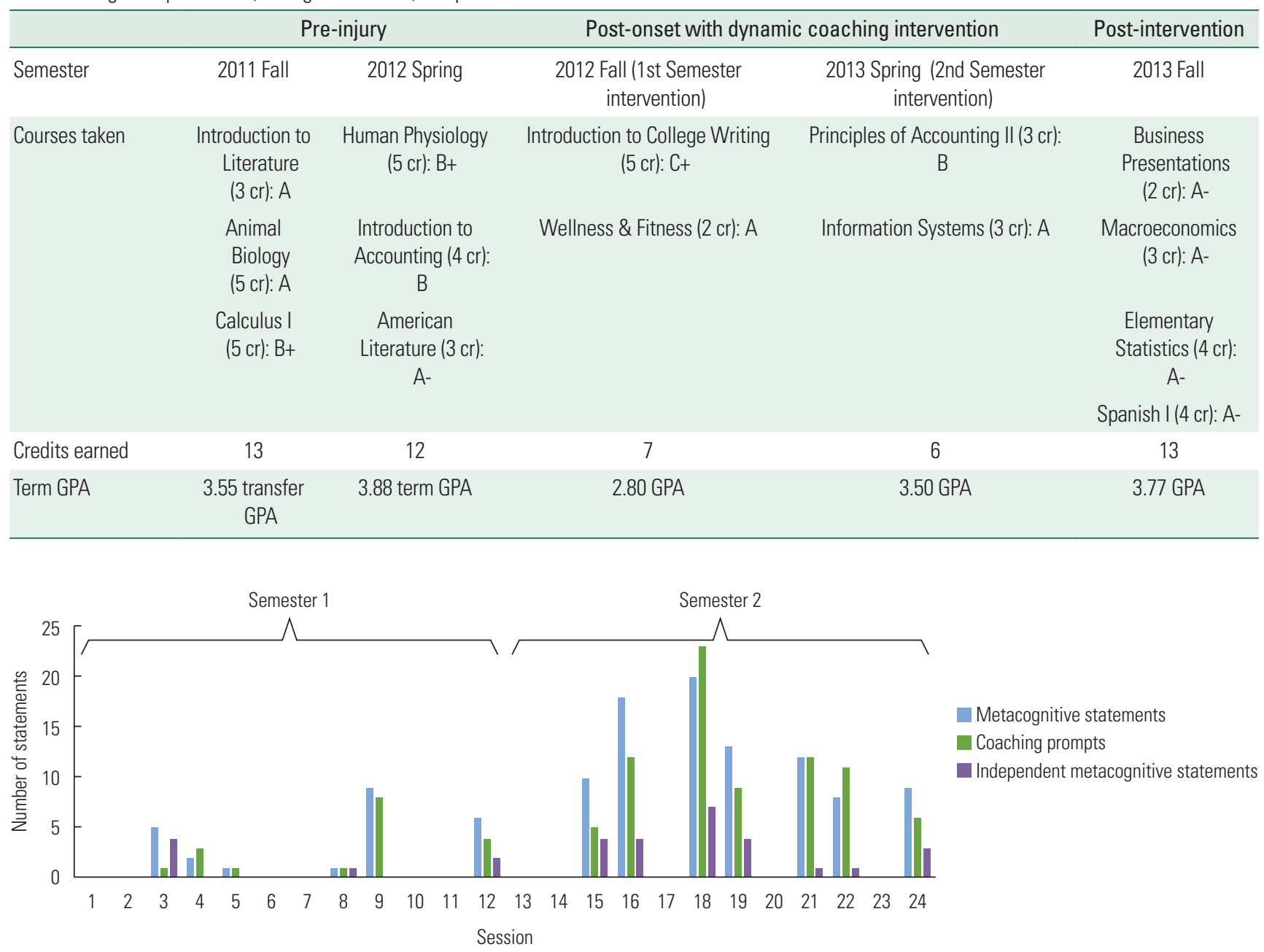

Figure 2. S1 Metacognitive statements and coaching prompts.

Comprehension both improved to 7, indicating no limitations of language vocational, avocational, or social activities.

S1's grades improved over the course of the intervention (Table 2). Pre-injury cumulative GPA was a 3.55 as a full-time PSEO student. During the first semester after her injury as well as the first semester of intervention, S1's GPA dropped to a 2.8 with a part-time, 7 credit load. As study strategies were implemented in the second semester of intervention, S1's accounting exam grades improved. Her exam scores increased by $\sim 10 \%$ per midterm exam: from a $\mathrm{C}$ to $\mathrm{B}$ and, finally, a low $\mathrm{A}$. She received a $B$ in this accounting class at the end of the semester. Her final GPA this semester improved back to a 3.5, but still with part-time, 6 credit status. Post-intervention, S1 was encouraged to return to full-time status and was able to improve her GPA again to a 3.77.

As another measure of intervention success, coaches mea- sured metacognitive statements during sessions over the course of two semesters (Figure 2). Use of prompted and independent metacognitive statements varied throughout the two semesters. Mean prompts, prompted metacognitive statements, and independent metacognitive statements all increased from the first to second semester See Table 3 for mean prompts per semester, mean prompted metacognitive statements per semester, and mean independent statements per semester for S1. Use of session time was also examined. Overall, efficiency of statements reflecting on-task behaviors to off-task was $59 \%$.

Other academic outcomes include completion of 24 out of 24 credits attempted during the time of intervention. S1 also completed 3 credits of Winterim courses and 7 credits during the summer, earning a 3.0 and 3.24 GPA, respectively.

Non-academic outcomes include S1 successfully maintain- 
Table 3. Prompted and independent metacognitive statements per semester

\begin{tabular}{lcc}
\hline & Semester 1 & Semester 2 \\
\hline Mean number of coaches prompts & $2.57(2.76)$ & $9.75(6.76)$ \\
Mean prompted metacognitive statements & $3.43(3.31)$ & $11.25(6.20)$ \\
Mean independent metacognitive statements & $1.00(1.53)$ & $3.00(2.27)$ \\
\hline
\end{tabular}

Standard deviation noted as $(S D)$.

Several sessions were not included in calculation of descriptive statistics. Testing was completed in weeks 1-2, session recordings failed in sessions 10, 11, 13, and 23. Sessions 6-7 were in the library and session 17 was a Skype call that did not follow typical session structure.

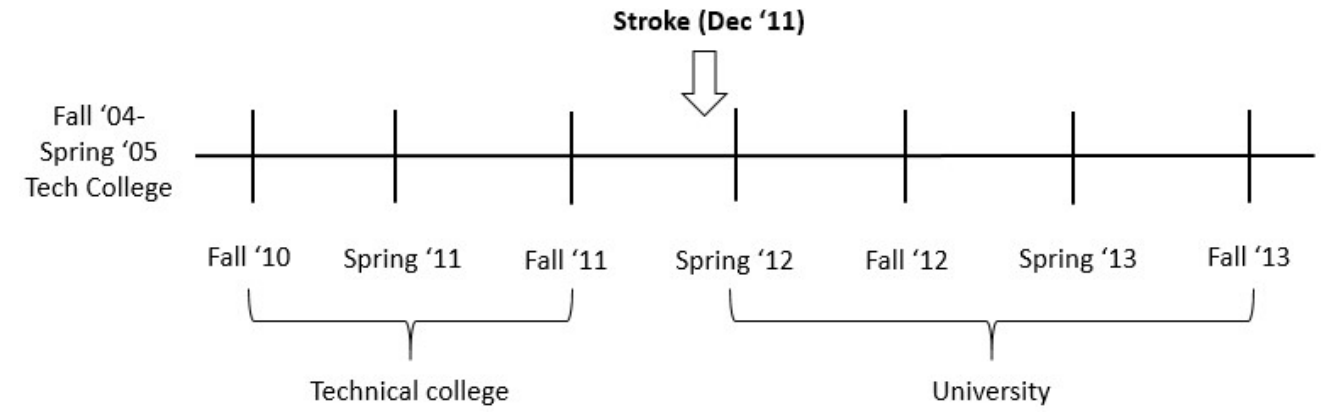

Figure 3. Timeline for S2, initial college education, onset of stroke, and return to university.

ing a part-time job and moving out of her mother's home to live independently.

Post-intervention outcomes include her application and admission to the University of Wisconsin - Eau Claire College of Business the fall following intervention.

\section{Case study 2 \\ Participant}

S2 was a 42-year-old female who was attempting to return to college following a cerebrovascular accident. Her hospital stay was three days. Outpatient speech therapy was only three weeks in duration. Prior to onset of the stroke, S2 had completed three semesters of college at a local technical college. Following onset of her stroke in December of 2011, she attempted to return to college at the University of Wisconsin Eau Claire university in late January of 2012. Because of her positive experiences with the SLPs who worked with her during rehabilitation, she began coursework in the CSD major, hopeful to become an SLP. She was referred to our dynamic coaching program from a faculty member in the CSD department who was familiar with her coursework challenges. Return to college and enrollment in the CSD major began when S2 was 23 days post-stroke and coaching interactions began one week into her third semester of returning to college postinjury. At the outset of coaching, she had some occasional anomia, mildly extended processing time when she became overwhelmed, mild impulsivity, distractibility, and impaired time sense and/or urgency. As is noted within the initial descriptions of participants, authors decided to include S2 in this intervention because her profile matched the purpose of the coaching program. She had impairments to executive function, including organization, attention, self-awareness, and self-regulation. Although she initially demonstrated aphasia post-onset, scores on standardized assessment reflected no ongoing effects of aphasia. Incidents of word finding difficulties were rare at the outset of the coaching program and did not appear to limit her directly in coursework. For a timeline of her stroke onset and return to college, please see Figure 3.

\section{Pre-intervention measures}

Pre-intervention measures replicated assessments used by Kennedy and Krause [9], including the RBANS [37], AMNART [38], FAVRES [39], and the CSS-BI [15]. Subscale scores from testing completed one week prior to intervention can be seen in Table 1.

\section{CSS-BI}

S2 identified five areas of difficulty out of 16 general categories listed on the CSS-BI. She reported experiencing challenges with decision-making problems, memory problems, organization problems, attention problems and headaches. Out of 
13 student experience statements, S2 agreed with three, acknowledging that she gets overwhelmed when studying, gets nervous before tests, and does not always understand the instructions for assignments. Challenges with time management or trouble prioritizing assignments and other meeting deadlines were not openly expressed. Troubles relating to others were not identified.

To examine potential effects of language impairments on study outcomes, the Adult Functional Communication Measures (FCM) of Spoken Language Expression and Comprehension were used to characterize expressive and receptive language [40]. Pre-intervention scores for Spoken Language Expression and Comprehension were both 6. A Spoken Language Expression score of 6 indicated that the person was able to communicate successfully in most contexts, although there were some limitations present in vocational, avocational, and social activities. A Comprehension score of 6 indicated the ability to understand with rare, minimal cueing for complex sentences.

\section{Coaching intervention}

During the first semester of intervention, S2 was enrolled in 12 credits, including chemistry issues (CHEM 100), a normal communication lab (CSD 258), phonetics (CSD 262), human geography (GEOG 111), and music appreciation (MUSI 110). She withdrew from chemistry midway through the semester. She participated in six of twelve weekly, 30-minute coaching sessions.

To address studying and learning, coaches assisted S2 with a variety of courses, although much of the time was focused on CSD courses. She refused any accommodations by the Center for Students with Disabilities, which is consistent with past report that students choose not to take advantage of resources offered to them [15]. Strategies used regularly included creating flash cards, self-quizzing, re-writing notes, recording class lectures, and concept mapping. Coaching session time was spent breaking up and organizing notes and identifying a plan for studying. Since the coach was also a CSD student, S2 would often try to steer the conversations in the direction of tutoring and direct assistance. Although the coach did not acquiesce to those attempts, it consumed a fair amount of time, as $\mathrm{S} 2$ was persistent in those attempts. The coach reminded S2 that she had been assigned to one personal teaching assistant for her phonetics course. The teaching assistant held office hours to review questions and go over tests and assignments. As such, the coach focused on strategy development by collaboratively initiating development of flash cards, concept mapping, and self-quizzing with the student.

S2 did not report any difficulty with time management on the CSS-BI. However, in the first semester of intervention, this domain was addressed in coaching sessions regularly. Common challenges for S2 included managing and prioritizing life events to balance time spent on school work and family. At times, S2 would become too overwhelmed with academic and non-academic demands and not attend class. At one point, she stated "I think with everything going on it kind of hit me. So, I kind of like totally blew off school on Monday. But I had to. I don't think I really put myself back at all..." Because of her inconsistency in attending coaching sessions, part of the focus was on attending meetings. This challenge was also an issue in attending teaching assistant and professor office hours. Beyond attending meetings, another point of emphasis was coming to meetings prepared. Again, this was an expectation for coaching sessions and the challenge carried over to meetings with teaching assistants and professors.

While relating to others was not identified on the CSS-BI, it was a regular challenge for S2. Issues addressed in coaching sessions included how to use a tutor, attending regular meetings with teaching assistants, studying with peers, and developing a support system to prevent becoming overwhelmed. In coaching sessions, S2 was encouraged and appeared to be on board with utilizing her resources but she did not follow through regularly.

In the second semester of intervention, S2 was initially enrolled in 14 credits but she dropped one 3-credit course in American Indian History and Culture. She remained enrolled in American Sign Language I (CSD 101), Anatomy and Physiology of the Speech and Hearing Mechanism (CSD 256), and Intermediate Algebra (MATH 20). S2 participated 6 of 12 weekly, 30-minute coaching sessions.

During the second semester, studying and learning intervention focused primarily on her CSD courses. At the outset of the semester, she demonstrated no carryover of first semester strategies. There was a return to emphasis on study strategies of the first semester but her implementation was inconsistent. While not one of her strongest strategies, sometimes she would simply revisit concepts that she did not understand. She remarked, "I'll go back and I'll re-read something if I feel like it doesn't make sense to me, and that does help." At times, coaching sessions seemed to gain momentum, where she increased study strategies and self-assessment ap- 
proaches. During periods of success, she became over confident and questioned her need for any support, which was followed by a decline in performance. When she became overwhelmed, she missed coaching sessions, becoming reactive, rather than proactive in her approach. She struggled to prioritize coursework with other life demands. When she struggled, she frequently blamed her struggles on people or factors outside of herself.

Time management and relating to others remained common concerns in the second semester but her self-regulation was inconsistent. She remarked, "That second semester... I was, 'I'm going to do this on my own I don't need any help!' And guess what, I don't have to do that! And it feels so good that I don't have to do that. I mean eventually, I'm going to have these big tests one day that I'm going to have to do on my own, and to do that I mean... This is why I'm here."

\section{Post-intervention measures}

Post-testing was completed four weeks after the last coaching session of semester two, since she discontinued attendance prior to the end of the semester. Her RBANS total score improved from the 17th to the 58th ( $>1 S D$ ), immediate memory improved from the 18th to the 25th, delayed memory from the 13th to the 34th, language from the 18th to the 25th, attention from the 8th to 84 th ( $>2 S D$ ), and visuospatial processing from the 84th to 96th percentile. AMNART scores remained stable (135.08 pre to 136 post). Total scores for FAVRES improved from 49th to 100th percentile for accuracy, 13th to 32nd percentile for rationale ( $>1 S D$ ), and 66th to 80th percentile for time. For a comparison of post-testing outcomes for both students, see Table 1 .

To examine potential effects of language impairments on study outcomes, the Adult Functional Communication Measures (FCM) of Spoken Language Expression and Comprehension were used to characterize expressive and receptive language [40]. Post-intervention scores for Spoken Language Expression and Comprehension remained at 6. A Spoken Language Expression score of 6 indicated that the person was able to communicate successfully in most contexts, although some limitations remained present in vocational, avocational, and social activities. A Comprehension score of 6 indicated the ability to understand with rare, minimal cueing for complex sentences.

S2's grades improved over the course of the intervention (Table 4). Pre-onset cumulative GPA at the Chippewa Valley Technical College was a 2.26, although the last two full semesters were 3.0. During the semester of her stroke, she earned a GPA of 1.59. Note that onset was near the end of that semester but clearly contributed to her failure in chemistry. Just a shorttime after her stroke onset, she returned to college, taking coursework in CSD and earning a GPA of 2.83 in her first semester, 3.16 in her second semester. At the outset of her third

Table 4. S2 grades prior to onset, during intervention, and post-intervention

\begin{tabular}{|c|c|c|c|c|c|c|c|c|c|c|}
\hline \multirow[b]{3}{*}{ Semester } & \multirow[b]{3}{*}{2004 Fall } & \multirow[b]{3}{*}{2005 Spring } & \multirow[b]{3}{*}{2010 Fall } & \multirow{3}{*}{2011 Spring } & \multirow{3}{*}{$\begin{array}{c}\begin{array}{c}\text { Onset (end } \\
\text { of term) }\end{array} \\
2011 \text { Fall }\end{array}$} & \multicolumn{4}{|c|}{ Post-onset and returned to courses } & \multirow{3}{*}{$\begin{array}{c}\text { Post- } \\
\text { intervention }\end{array}$} \\
\hline & & & & & & \multirow{2}{*}{\multicolumn{2}{|c|}{$\begin{array}{c}\begin{array}{c}\text { Post-onset but no } \\
\text { intervention }\end{array} \\
2012 \text { Spring } 2012 \text { Fall }\end{array}$}} & \multicolumn{2}{|c|}{$\begin{array}{c}\text { Post-onset with dynamic } \\
\text { coaching intervention }\end{array}$} & \\
\hline & & & & & & & & $\begin{array}{l}2013 \text { Spring } \\
\text { (1st Semester } \\
\text { Intervention) }\end{array}$ & $\begin{array}{l}2013 \text { Fall (2nd } \\
\text { Semester } \\
\text { Intervention) }\end{array}$ & \\
\hline $\begin{array}{c}\text { Courses } \\
\text { taken }\end{array}$ & $\begin{array}{l}\text { PSYC } 100(F) \\
\text { WRIT } 801 \\
\text { (F) ENGL } \\
171(F)\end{array}$ & $\begin{array}{l}\text { PSYC } 930 \text { (F) } \\
\text { WRIT } 801 \\
\text { (F) }\end{array}$ & $\begin{array}{l}\text { PSYC } 100 \\
\text { (B-) MATH } \\
10 \text { (A-) CJ } \\
202 \text { (A-) } \\
\text { WRIT } 801 \\
\text { (B-) }\end{array}$ & $\begin{array}{l}\text { PSYC } 230 \\
(B+) \text { POLS } \\
110 \text { (A-) } \\
\text { BIOL 100 } \\
\text { (B-) ENGL } \\
907 \mathrm{~L}(\mathrm{C}+)\end{array}$ & $\begin{array}{l}\text { SOC } 101 \\
\text { (B+) CHEM } \\
806(F) \\
\text { ENGL } 110 \\
\text { (C) }\end{array}$ & $\begin{array}{l}\text { CSD } 101 \text { (F) } \\
\text { CSD } 256 \\
\text { (C-) CSD } \\
257 \text { (B-) } \\
\text { CSD 262 } \\
\text { (C-) GEN } \\
100 \text { (B+) }\end{array}$ & $\begin{array}{l}\text { AIS } 161 \text { (C+) } \\
\text { ENGL 150 } \\
\text { (A) GEOG } \\
111 \text { (C-) } \\
\text { MATH } 20 \\
\text { (C-) }\end{array}$ & $\begin{array}{r}\text { CHEM } 100 \text { (W) } \\
\text { CSD } 258(\mathrm{~A}-) \\
\text { CSD } 262(\mathrm{~B}-) \\
\text { GEOG } 111(\mathrm{~B}) \\
\text { MUSI } 110(\mathrm{~A})\end{array}$ & $\begin{array}{l}\text { AIS } 101(\mathrm{~W}) \\
\text { CSD } 101(\mathrm{~A}-) \\
\text { CSD } 256(\mathrm{~B}) \\
\text { MATH } 20 \\
(\mathrm{~B}+)\end{array}$ & $\begin{array}{l}\text { CSD } 331 \text { (W) } \\
\text { CSD } 352 \text { (W) } \\
\text { CSD } 353 \text { (W) } \\
\text { MATH } 246 \\
\text { (W) }\end{array}$ \\
\hline $\begin{array}{l}\text { Credits } \\
\text { taken/ } \\
\text { repeated }\end{array}$ & 8 & 6 & 12 & 13 & 10 & 13 & 13 & $12 / 7$ & $14 / 8$ & 15 \\
\hline $\begin{array}{l}\text { Credits } \\
\text { earned }\end{array}$ & 0 & 0 & 12 & 13 & 6 & 4 & 6 & 9 & 11 & ${ }^{*} 0$ \\
\hline Term GPA & 0.0 & 0.0 & 3.2 & 2.98 & 1.59 & 2.83 & 3.16 & 3.33 & 3.30 & 0.0 \\
\hline
\end{tabular}

Note that $\mathrm{S} 2$ dropped all courses her first semester post-intervention, earning 0 credits and decreasing GPA. 


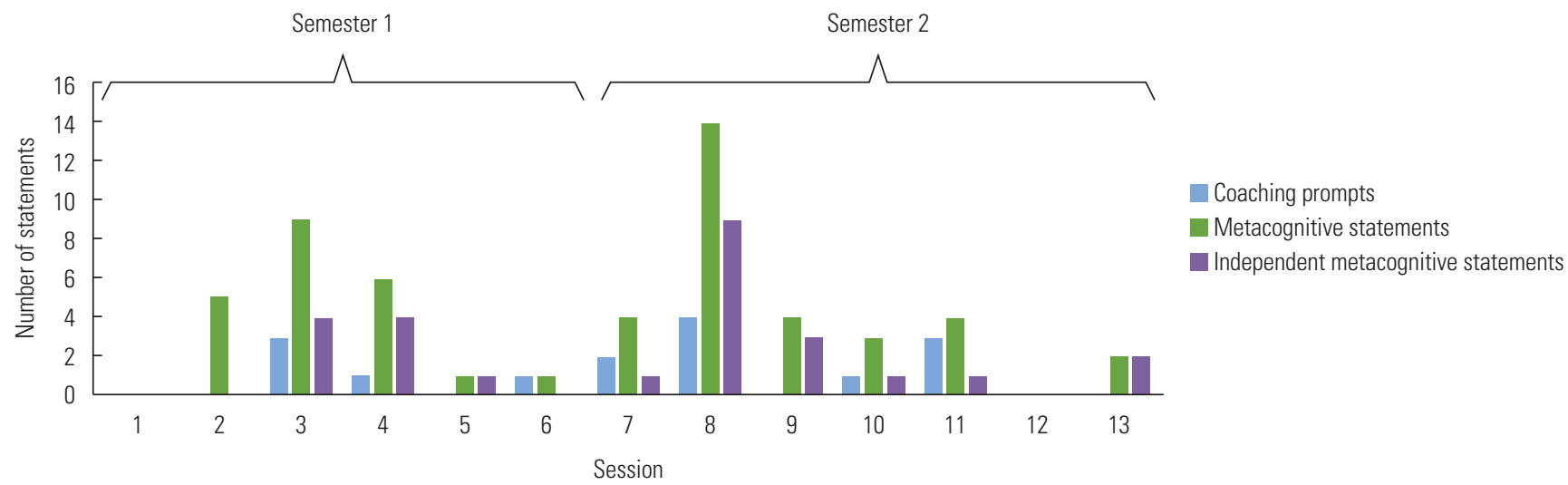

Figure 4. S2 Metacognitive statements and coaching prompts.

Table 5. Prompted and independent metacognitive statements per semester

\begin{tabular}{lcc}
\hline & Semester 1 & Semester 2 \\
\hline Mean number of coaches prompts & $1(1.22)$ & $1.67(1.63)$ \\
Mean prompted metacognitive statements & $4.4(3.43)$ & $5.16(4.40)$ \\
Mean independent metacognitive statements & $1.8(2.05)$ & $2.83(3.12)$ \\
\hline
\end{tabular}

Standard deviation noted as $(S D)$.

Two sessions were not included in calculation of descriptive statistics. Testing was completed in session 1 and session 12 was primarily informal counseling.

semester at the university she began participation in the dynamic coaching program, earning a 3.33 GPA. In her second semester in the program, she earned a comparable 3.30 GPA. Unfortunately, she was unable to sustain that success in her first semester post-intervention. Struggles in coursework, coupled with challenging demands at home led her to withdraw from all of her courses.

Coaches also measured metacognitive statements during sessions over the course of two semesters, as a measure of intervention success (Figure 4). Use of prompted and independent metacognitive statements varied throughout the two semesters. Mean prompts, prompted metacognitive statements, and independent metacognitive statements all increased from the first to second semester. See Table 5 for mean prompts per semester, mean prompted metacognitive statements per semester, and mean independent statements per semester for S2. Production of metacognitive statements was strongest at the beginning of each semester (i.e., sessions 2-4 of the first semester and sessions 7-11 of the second semester). This corresponded with a steady but limited number of coaching prompts per session. Use of session time was also examined. Overall, efficiency of statements reflecting on-task behaviors to off-task was $45 \%$.

Non-academic factors included S2 ongoing challenges with balancing schoolwork with her every day duties at home with her family. While both were certainly important to her, she became overwhelmed with workload in both contexts, which caused her to withdraw from use of time management strategies in both contexts.

Post-intervention outcomes include her withdrawal from all courses in the first semester, post-intervention. She did return to enroll in two more semesters at the university but withdrew early each of those semesters from all courses.

\section{DISCUSSION}

The current replication of a dynamic, individualized coaching builds upon findings from previous investigations by Kennedy and colleagues [6-10]. Importantly, a key finding is that the intervention needs to be individualized to suit the needs of the individual with an acquired brain injury.

\section{Case 1 outcomes}

S1 made substantial gains on behavioral measures such as the RBANS from pre- to post-testing. While the coaching intervention may have been a factor in those gains, it is not likely that those gains can be directly attributed to the current intervention. This is also true for gains on the FAVRES and AMN- 
ART. Language status was further validated through FCMs for Spoken Language and Comprehension. Both improved from a score of 6 from pre-intervention to a score of 7 post-intervention ratings. $S 1$ did identify a reduction in perceived areas of difficulty on the CSS-BI from pre- to post-testing. Initially, she identified six areas of difficulty of the 16 general categories. Following the intervention, she gained skills in three of those areas: studying and learning, time management, and relating to others. S1's GPA steadily rose from the onset of intervention at 2.80 first semester to 3.5 during the second semester, and 3.77 post-intervention. This is consistent with her pre-injury GPA. Further, she worked her way from half-time successfully to fulltime enrollment by post-intervention. A steady increase in use of prompted and independent metacognitve statements was noted over the course of the two semesters of intervention, which paralleled an increase in coaching prompts per session. Metacognitive statements represent evidence of self-awareness and self-regulation, particularly regarding use of strategies to support completion of work and preparation for examinations and other summative measures. Along with direct academic gains, she was able to move out of her mother's home into an apartment, decreasing her overall dependence on her mother for support in planning, scheduling appointments, and everyday living. She was accepted into her degree program in the fall semester proceeding the coaching intervention.

\section{Case 2 outcomes}

S2 also made substantial gains on behavioral measures such as the RBANS, which are likely a product of many factors beyond the current intervention. While the coaching intervention may have contributed in some way, gains cannot be directly attributed to the intervention. The same can be said about gains on the FAVRES and AMNART. Language status was further validated through FCMs for Spoken Language and Comprehension. Both remained at a stable rating of 6 from pre- to post-intervention ratings. While this does not eliminate the possibility that language status affected intervention outcomes, it does suggest any affects would have been marginal. S2 identified five areas of difficulty out of the 16 general categories of the CSS-BI. Following the intervention, she made inconsistent gains in three of those areas: studying and learning, time management, and relating to others. While she used some strategies, such as revisiting concepts that she did not understand or re-reading, implementation was inconsistent. The coaches' field notes indicate that she seemed to gain momentum in proactive, self-assessment and studying strategies when she attended sessions regularly. However, periods of success were often coupled with over confidence and missing coaching sessions. This cycle resulted in her becoming overwhelmed and abandoning strategies. It should be noted that balancing school work and obligations to her family may have exacerbated these effects. Self-regulation for time management and relating to others followed that same pattern. She made gains in academic performance while in the coaching program, increasing her GPA from 2.83 and 3.16 in her first two semesters post-onset but prior to coaching, to 3.33 in her first semester of coaching and 3.30 in the second semester. She withdrew from some part of her credit load in each semester post-onset, which is consistent with past investigations which suggest $81 \%$ reduce their course load or even drop out $[10,15]$. Unfortunately, she was not able to sustain that success post-intervention and she ultimately withdrew from all of her courses. Use of metacognitve statements varied widely over the course of the two semesters of intervention. In spite of inconsistent attendance, gains were made in use of prompted and independent metacognitive statements were made from the first to second semester. Coaching prompts per session were limited, which could have affected both prompted and independent metacognitive statements. The coaches' field notes indicate that much of her time was focused on redirecting, as S2 wanted her to tutor/reteach the content rather than focus on implementing learning strategies.

\section{General conclusions}

Inconsistencies in the way that $\mathrm{S} 1$ and $\mathrm{S} 2$ responded to the coaching intervention are consistent with past investigations $[9,10]$. Both participants demonstrated evidence that the approach can work when attendance is consistent and motivation is strong. S1 responded to the coaches prompts to elicit her own potential solutions by frequently identifying specific learning strategies. Her coach responded by affirming, reflecting, and summarizing those self-identified strategies. Competing demands outside of school and personal factors contributed to inconsistency in S2. While a motivational interviewing approach was used to augment coaching with both students, implementation varied across students, along with other factors that made it more difficult to implement with S2. Locus of control seemed to be externalized for S2, which may have been further affected by the fact that S2 was a CSD undergraduate. As an undergraduate CSD student being coached 
by a CSD graduate student, she knew that her coach had successfully navigated and had prior knowledge about each of her courses within the major. As a result, she persistently attempted to make the session an opportunity for direct tutoring of class concepts, rather than focus on strategies. The tendency of some participants to want coaches to tutor or reteach them rather than focus on strategic behavior had also been noted in previous investigations $[9,10]$.

\section{Limitations}

While the present investigation adds to our understanding of the variability (heterogeneity) and what is necessary to implement a complex, individualized coaching intervention, there are several limitations. Of course, the small number of participants limits our ability to generalize outcomes. Part of the intent of this intervention was to add to the number of participants from previous investigations. While attempts were made to follow protocols consistent with previous investigations, individual factors ultimately compromised the consistency to some extent. Given the disparity in performance outcomes by $\mathrm{S} 1$ and $\mathrm{S} 2$, the case study design was a limitation. While the intervention framework was consistent across participants, individualized modifications and needs limit our ability to generalize these outcomes. The primary impairments of the students were similar, although age and etiology differed, limiting our ability to make clear statements about differences in outcomes. S2 was a student within the CSD major, which created unique challenges. Whether or not that student would have persisted so consistently on asking the coach to tutor/re-teach if she had been from a different major is impossible to know. Regardless, she did and that had an impact on the nature of the services delivered from the coach. That is not to say that the coach did not implement the techniques appropriately but rather that she had to spend a great deal of time redirecting to the intervention, which ultimately reduced her ability to prompt metacognitive strategies. Implementation of motivational interviewing techniques was also impacted by the response of participants. Both coaches implemented basic elements of the approach, including openended questions, affirmation, reflection, and summarization techniques to elicit each participant's own solutions for addressing challenges they encountered. The tendency of S2 to persistently seek external solutions made this approach challenging to implement. The primary consequence was fewer opportunities to affirm, reflect statements, and summarize strategic solutions identified by S2.

\section{ACKNOWLEDGMENTS}

This project was made possible, in part, through a Blugold Research Fellowship for the second author. Special thanks to Dr. Matthew Evans who oversees Blugold Fellows and mentored author two throughout the process. Thanks to the Office of Research and Sponsored Programs for financial support for the fellowship and this project. A special thanks to Dr. Mary Kennedy and Dr. Miriam Krause for their consultations. Finally, we wish to thank both clients for their participation.

\section{REFERENCES}

1. Centers for Disease Control and Prevention. (2015). Report to congress on traumatic brain injury in the United States: epidemiology and rehabilitation. National Center for Injury Prevention and Control; Division of Unintentional Injury Prevention. Atlanta, GA.

2. Selassie AW, Zaloshnja E, Langlois JA, Miller T, Jones P, Steiner C Incidence of long-term disability following traumatic brain injury hospitalization, United States, 2003. JHTR. 2008;23:123-131.

3. Thurman DJ, Alverson C, Dunn KA, Guerrero J, Sniezek JE. Traumatic brain injury in the United States: a public health perspective. JHTR. 1999;14:602-615.

4. Zaloshnja E, Miller T, Langlois JA, Selassie AW. Prevalence of longterm disability from traumatic brain injury in the civilian population of the United States, 2005. JHTR. 2008;23:394-400.

5. Faul M, Xu L, Wald MM, Coronado VG. Traumatic brain injury in the United States. Emergency Department Visits, Hospitalizations and Deaths, 2006-2010. 2010; published online.

6. O'Brien KH, Schellinger SK, Kennedy MR. Self-regulation strategies used by students with brain injury while transitioning to college. NeuroRehabilitation. 2018;(Preprint):1-11.

7. Kennedy MR, Krause MO, O’Brien KH. Psychometric properties of the college survey for students with brain injury: Individuals with and without traumatic brain injury. Brain Injury. 2014;28: 1748-1757.

8. Kennedy MR, O'Brien KH, Krause MO. Bridging person-centered outcomes and therapeutic processes for college students with traumatic brain injury. SIG 2 Perspectives on Neurophysiology and Neurogenic Speech and Language Disorders. 2012;22:143151.

9. Kennedy MR, Krause M. Self-regulated learning in a dynamic coaching model for supporting college students with traumatic brain injury: two case reports. JHTR. 2011;26:212-223.

10. Kennedy MR, Krause MO. Academic experiences of adults with and without traumatic brain injury using the College Survey for Students with Brain Injury (CSS-BI). Brain Injury. 2010;24:325.

11. Krause M, Kennedy MR. Metamemory adjustments over time in adults with and without traumatic brain injury. Brain Injury. 2009; 23:965-972. 
12. Kennedy M, Carney E, Peters S. Predictions of recall and study strategy decisions after diffuse brain injury. Brain Injury. 2003;17: 1043-1064.

13. Kennedy MR, Yorkston K. Accuracy of metamemory after traumatic brain injury: Predictions during verbal learning. JSLHR. 2000;43:1072-1086.

14. Kennedy MR, Krause MO. College survey for students with brain injury. 2009; Retrieved February, 20, 2015.

15. Kennedy M, Krause M, Turkstra L. An electronic survey about college experiences after traumatic brain injury. NeuroRehabilitation. 2008;23:511-520.

16. Dawson D, Schwartz M, Winocur G, Stuss D. Return to productivity following traumatic brain injury: Cognitive, psychological, physical, spiritual, and environmental correlates. Disability \& Rehabilitation. 2007;29:301-313.

17. Wagner M, Newman L, Cameto R, Garza N, Levine P. After high school: a first look at the postschool experiences of youth with disabilities. A report from the National Longitudinal Transition Study-2 (NLTS2). 2005; Online submission.

18. Stuss D, Alexander M. Executive functions and the frontal lobes: a conceptual view. Psychological Research. 2000;63:289-298.

19. Souchay C, Isingrini M. Age-related differences in the relation between monitoring and control of learning. Experimental Aging Research. 2004;30:179-193.

20. Leonesio R, Leonesio R, Nelson T. Do different metamemory judgments tap the same underlying aspects of memory? Journal of Experimental Psychology, Learning, Memory \& Cognition. 1990;16:464-470.

21. Kennedy MR, Yorkston K. The effects of frontal injury on "on-line" self-monitoring during verbal learning by adults with diffuse brain injury. Neuropsychological Rehabilitation. 2004;14:449-465.

22. Nelson T, Dunlosky J. When people's judgments of learning (jols) are extremely accurate at predicting subsequent recall: the "delayed-jol effect”. Psychological Science (Wiley-Blackwell). 1991;2: 267-270.

23. Nelson T, Dunlosky J. How shall we explain the delayed-judgment-of-learning effect?. Psychological Science (Wiley-Blackwell). 1992; 3:317-318.

24. Giovanello KS, Verfaellie M. Memory systems of the brain: a cognitive neuropsychological analysis. Seminars in Speech and Language. 2001;22:109-118.

25. Kennedy MR. Self-monitoring recall during two tasks after traumatic brain injury: A preliminary study. AJSLP. 2004;13:142-154.

26. Kennedy MR. Retrospective confidence judgments made by adults with traumatic brain injury: Relative and absolute accuracy. Brain Injury. 2001;15:469-487.

27. Murray LL, Ramage AE, Hopper T. Memory impairments in adults with neurogenic communication disorders. Seminars in Speech and Language. 2001;22:129-138.

28. Novack TA, Alderson AL, Bush, BA, Meythaler JM, Canupp K. Cognitive and functional recovery at 6 and 12 months post-TBI. Brain Injury. 2000;14:987-996.

29. Shum DH, Harris D, O'Gorman JG. Effects of severe traumatic brain injury on visual memory. Journal of Clinical and Experimental Neuropsychology. 2000;22:25-39.

30. Turkstra LS, Holland AL. Assessment of syntax after adolescent brain injury: Effects of memory on test performance. JSLHR. 1998; 41:137-149.

31. Vakil E, Biederman Y, Liran G, Groswasser Z, Aberbuch S. Headinjured patients and control group: Implicit versus explicit measures of frequency of occurrence. Journal of Clinical and Experimental Neuropsychology. 1994;16:539-546.

32. Douglas JM, Bracy CA, Snow PC. Return to work and social communication ability following severe traumatic brain injury. JSLHR. 2016;59:511-520.

33. Galski T, Tompkins C, Johnston MV. Competence in discourse as a measure of social integration and quality of life in persons with traumatic brain injury. Brain Injury. 1998;12:769-782.

34. Meulenbroek P, Turkstra LS. Job stability in skilled work and communication ability after moderate-severe traumatic brain injury. Disability and Rehabilitation. 2016;38:452-461.

35. Hux K, Bush E, Zickefoose S, Holmberg M, Henderson A, Simanek G. Exploring the study skills and accommodations used by college student survivors of traumatic brain injury. Brain Injury. 2010;24: 13-26.

36. United States. Department of Health, Education, and Welfare. Office for Civil Rights. Section 504 of the Rehabilitation act of 1973: fact sheet: handicapped persons rights under Federal law. Washington: Dept. of Health, Education, and Welfare, Office of the Secretary, Office for Civil Rights. 1978.

37. Randolph C. Repeatable Battery for the Assessment of Neuropsychological Status (RBANS). 1998; San Antonio: Psychological Corporation.

38. Nelson HE, Willison JR. The Revised National Adult Reading Test Manual, NFER-Nelson, 1991; Windsor, UK.

39. MacDonald S. FAVRES: Functional Assessment of Verbal Reasoning and Executive Strategies. 2005; CCD Publishing.

40. American Speech-Language Hearing Association. National Outcomes Measurement System (NOMS): Adult speech-language pathology user's guide. Rockville, MD: 2013.

41. Miller WR, Rollnick S. Motivational interviewing: helping people change. 2012; New York. NY: Guilford Press.

42. Bogdan RC, Biklen SK. Qualitative research for education: An introduction to theories and methods. 2003; Thousand Oaks, CA: Sage Publications, Inc. 